discriminate between workers at a wider range on each scale, and detect changes in IWP. In conclusion, the IWPQ seems to be a suitable instrument to study IWP in occupational epidemiology.

\section{ASSOCIATION OF PSYCHOTHERAPY WITH LONG-TERM DISABILITY BENEFIT CLAIM CLOSURE AMONG PATIENTS DISABLED DUE TO DEPRESSION}

${ }^{1}$ S E Ebrahim, 'Busse, ${ }^{1}$ Walter, ${ }^{1}$ Heels-Ansdell, 'Hanna, ${ }^{1}$ Patelis-Siotis, ${ }^{2}$ Bellman, ${ }^{1}$ Guyatt. ${ }^{1}$ McMaster University, Toronto, Canada; ${ }^{2}$ Sun Life Financial, Toronto, Canada

10.1136/oemed-2013-101717.52

Objectives To evaluate the effect of psychotherapy for depression in patients receiving disability benefits.

Methods Using administrative data from a large Canadian, private, disability insurer, we evaluated the association between the provision of psychotherapy and other potentially predictive factors with time to long-term disability (LTD) claim closure.

Results We analysed 10,338 LTD claims in which depression was the primary disabling complaint. Depression management included psychotherapy in $1580(15.3 \%)$ LTD claims. In our adjusted analyses, receipt of psychotherapy was associated with faster claim closure (hazard ratio $[\mathrm{HR}]=1.42 ; 95 \%$ confidence interval $[\mathrm{CI}]=1.33$ to 1.52$)$. Older age per decade $(0.83[0.80$ to 0.85 ] respectively), a primary diagnosis of recurrent depression (0.80 [0.74 to 0.87$])$ versus major depression, a secondary psychological (0.77 [0.72 to 0.81$])$, or non-psychological diagnosis $(0.66$ [0.61 to 0.71$])$, a longer time to claim approval $(0.995$ [0.992 to 0.998$]$, and an administrative services only policy ( 0.87 [ 0.78 to 0.96 ] or refund policy ( 0.73 [0.69 to 0.77$]$ ) versus non-refund policy were associated with longer time to claim closure. Residing in the Prairies (1.46 [1.35 to 1.57]) and Quebec (1.93 [1.82 to 2.05]) versus Ontario were associated with faster LTD claim closure.

Conclusions We found multiple factors, including psychotherapy, which were predictive of time to LTD claim closure. Our findings may however be influenced by selection bias and other biases that present challenges to the analysis and interpretation of administrative data, and highlight the need for well-designed prospective studies.

\section{ASSOCIATIONS OF THE PSYCHOSOCIAL WORK ENVIRONMENT FACTORS WITH THE MENTAL HEALTH DISORDERS IN NURSING PROFESSION}

T Freimann, Lünekund, Merisalu. University of Tartu, Tartu, Estonia

10.1136/oemed-2013-101717.53

Objective This study examined the associations of work environment factors with the mental health disorders in nursing profession.

Methods A cross-sectional survey was carried out among registered nurses in the Tartu University Hospital. The electronic questionnaire was sent to all 906 full staff nurses working in hospital. The Estonian translation of the Copenhagen Psychosocial Questionnaire, version II (COPSOQ II) was used to measure psychosocial work environment dimensions and mental health disorders. Data were analysed using the SPSS version 18 and Statistical Software R. Descriptive statistics was used to assess means and standard deviations for psychosocial risk factors and mental health disorders. Binary logistic regression analysis was used to observe relationships between risk factors and mental health disorders. The results were summarised by OR-s with 95\% CI-s.
Results A total 404 questionnaires (45\%) were used in the analysis. The average age of the study group was 40.2 years (SD 10.8 ) and most of respondents were women (98.3\%). The mental health indicators showed relatively high average values of burnout and stress among nurses. High average scores of positive work characteristics (meaning of work, role clarity, social relationships at work and mutual trust between employees) in a 100 point scale were detected. High average scores were measured also on the negative work characteristics as work-family conflict, work pace, emotional and cognitive demands. The increased risk for mental health disorders was caused by work-family conflict, above-average quantitative and emotional demands and other factors. Risk for mental health disorders was decreased by above-average justice and respect, commitment to the workplace, job satisfaction and other factors.

Conclusions Our study confirmed that there are strong relationship between psychosocial risk factors and mental disorders. The present study refers to the urgent need for preventive strategies to reduce the psychosocial stress factors as the main causes of mental health problems.

\section{Session: H. Cancer epidemiology I}

\section{OCCUPATIONAL CANCERS RISK PERCEPTION IN IRANIAN INDUSTRIAL WORKERS}

Dr Zare Sakhvidi, Barkhordari, Halvani, F. Zare Sakhvidi, Dehghan, Firoozi, Dr Morowatisharifa. Yazd, Iran

\subsection{6/oemed-2013-101717.54}

Objectives This cross sectional study examined the occupational cancer risk perception among 269 Iranian industrial workers according to their knowledge, job titles hazard and demographical properties.

Methods The structured questionnaire was used to measure participants knowledge and perception toward occupational cancers $(\alpha=0.72)$. There was significant difference in both knowledge and perception about occupational cancers in different age, and educational groups.

Results It was significant relation between knowledge and perception ( $\mathrm{p}$-value $=0.001, \mathrm{r}^{2}=0.323$ ). True answer to some questions was less than 20 percent. An optimistic bias was found in participant's perception. We developed a path analytical model for occupational cancers risk perception according to these findings.

Conclusions Our findings prove that cancers risk perception in industrial workforces is affected by several factors. Another important finding in our results is the differences between our findings and other studies about cancer risk perception in general population. It seems that there is different model for perception of occupational cancers in workforces. Further efforts should be placed in the training of workers to enhance their knowledge and subsequently their perception toward occupational cancers.

\section{AN HISTORICAL COHORT STUDY OF WORKERS IN THE} UK HARD-METAL INDUSTRY

${ }^{1} \mathrm{M}$ McElvenny, ${ }^{1}$ Cherrie, ${ }^{2}$ Buchanich, ${ }^{3}$ Kennedy, ${ }^{3}$ Esmen, ${ }^{2}$ Marsh. ${ }^{1}$ Institute of Occupational Medicine, Edinburgh, United Kingdom; '2University of Pittsburgh, Pittsburgh, United States of America; ${ }^{3}$ University of Illinois at Chicago, Chicago, United States of America

10.1136/oemed-2013-101717.55 